\title{
ESTUDO DE CASO: ANÁLISE DO GRAU DE INOVAÇÃO EM QUATRO EMPRESAS DO RAMO DE TECNOLOGIA DA INFORMAÇÃO E COMUNICAÇÃO - TICS, ATRAVÉS DA METODOLOGIA RADAR DA INOVAÇÃO
}

\author{
Carlos Raniel Domingues \\ Isabel Barros Rasia \\ Janaina Mendes Oliveira \\ Paulo Pitzer Rasia \\ Gustavo Rosa Borges \\ Cristine Hermann Nodari \\ ranidomingues@gmail.com \\ cristieducare@gmail.com \\ janainamende@uol.com.br \\ paulo.rasia.rs@gmail.com \\ gustavodarosaborges@gmail.com \\ cristine.nodari@gmail.com \\ Fundação Universidade Regional de Blumenau - FURB
}

Resumo. O artigo analisou o grau de inovação de quatro empresas de Tecnologia da Informação e Comunicação (TICs) da cidade de Pelotas/RS. Utilizou-se a metodologia do Radar da Inovação em que a empresa pode inovar, denominada de dimensões da inovação Sawhney et al (2006) e Bachmann e Destefani (2008). Os resultados mostraram que a inovação tem maior presença na dimensão ambiência inovadora, com ambiente informal, pouco burocrático que propiciou a geração de novas ideias. Entretanto, a dimensão presença possui o menor grau de inovação, sendo ineficaz em propor novas formas de distribuição dos produtos/serviços ou aprimorar os pontos já existentes de forma inovadora. Identificou-se a importância da inovação e do planejamento, evidenciou-se uma amplitude de formas para inovar nas empresas.

Abstract. The article examines the innovation degree of four company of Information and Communication Technology (ICTs) at city of Pelotas / RS. It was used the methodology Innovation Radar, called dimensions of innovation Sawhney et al (2006) and Bachmann and Destefani (2008). ). The results showed that innovation has greater presence in the dimension ambience innovative, with informal atmosphere, little bureaucracy that generated the new ideas. However, presence dimension has the lowest degree of innovation, being ineffective in proposing new forms of distribution of products / services or improve existing points innovatively. it was identified the importance of innovation and planning, it was evidenced various ways to innovate in company.

\section{Introdução}

Atualmente presenciamos um mercado dinâmico e de constante movimentação, o sucesso das empresas cada vez mais fica fadado em sua capacidade de mudar o que oferece ao mercado e as formas como cria entrega seus produtos (BESANT; TIDD,

R. Eletr. do Alto Vale do Itajaí - REAVI, v. 5, n. 8, p. 01-13, dez., 2016 ISSN: 2316-4190, DOI: 10.5965/231641900508201682 
2009). A inovação é um potencial impulsionador de uma economia, o desenvolvimento de uma determinada região até mesmo de um país é dependente da capacidade das empresas inovarem (SCHUMPETER, 1985). Inovar assume diversos fatores de uma empresa e não somente o produto ou um serviço novo, um exemplo disso é a empresa $3 \mathrm{M}$ Brasil que inovou em seu ambiente organizacional, onde os 108 funcionários do laboratório de desenvolvimento de produtos, em Sumaré (São Paulo), têm todas as semanas $15 \%$ do horário de trabalho para exercitar a criatividade. Nesse período, ficam proibidas as tarefas burocráticas. Este fato caracteriza uma inovação na ambiência inovadora.

Porém, inovar não limita-se apenas ao pensamento inovador ou como dito por especialistas da área de negócios "o pensamento fora da caixa", é mais abrangente, requer que todos os fatores determinantes estejam estreitamente alinhados com o negócio e o propósito de inovar, e da mesma forma ser tratado como um processo, gerenciável e que ocorra de maneira continua. Se valendo deste pressuposto instiga-se como poderia ser verificado, avaliado ou mensurado a inovação em uma empresa. Para a Organização para a Cooperação e Desenvolvimento Econômico (OCDE, 2005) através dos indicadores de patentes registradas e o percentual do faturamento aplicado em pesquisa e desenvolvimento (P\&D) são possíveis mensurar a inovação na empresa, entretanto Bachmann e Destefani (2008) esclarecem que este tipo de indicador de inovação não se adéqua as micro e pequena empresas brasileiras, visto que não é algo de comum prática por parte dos gestores, por exemplo, o registro de patentes. Bachmann e Destefani (2008) sugerem como forma de mensurar a atividade inovadora a utilização da metodologia Radar Da Inovação desenvolvida por (SAWHNEY; WOLCOTT; ARRONIZ, 2006).

A fim de estudar e compreender a metodologia Radar Da Inovação determinouse no contexto local um publico alvo para esta investigação, que ficaram definidos como o setor de serviços e Micro e Pequena Empresa (MPE) de Tecnologia da Informação e Comunicação (TICs). A escolha de empresas TICs é fundamentada conforme a observação de Barret (2015) que destaca que na abordagem contemporânea dos processos de inovação em serviço, destacam-se as TICs como ferramentas tecnológicas utilizadas na prestação de serviços, que contribuem para a produtividade e eficiência das empresas e que podem, ao longo do tempo, levar a mercados inteiramente novos. Outro fator é o crescimento do mercado das TICs que está cada vez mais acessível e promissor, segundo Grando (2012) o baixo investimento de capital em estrutura aliados a criatividade e habilidades pessoais são atrativos aos empreendedores desta área.

Neste contexto o tema do estudo é a inovação, e a pergunta de pesquisa buscou responder: como as empresas do ramo das TICs inovam? E se inovam, em quais áreas? Consoante a isso formulou-se o objetivo do presente artigo que é avaliar o grau de inovação em quatro empresas de tecnologia da informação e comunicação da cidade de Pelotas, através da metodologia Radar da Inovação. Da mesma forma procura-se evidenciar quais são as dimensões que as empresas pesquisadas concentraram as suas inovações

\section{Fundamentação Teórica}

Realizou-se uma pesquisa bibliográfica sobre o tema inovação, a partir da teoria Schumpeteriana, para estabelecer uma relação com outros estudos sobre a inovação com ênfase em serviços, sobre as tipologias da inovação e as dimensões da inovação, radar da inovação e, por fim, a ambiência inovadora adicionada na avaliação. 


\subsection{Inovação}

Entende-se que a inovação é um recurso fundamental para gerar valor à empresa bem como obter diferencial competitivo. Todavia essa afirmativa trata de uma visão contemporânea proveniente de uma evolução teórica do termo inovação, pelo qual renomados autores fundamentaram esta percepção. A principal contribuição fundamentadora pertence à Schumpter (1985), no qual define a inovação, como um mecanismo central capaz de promover o desenvolvimento econômico por meio de rupturas nos processos padrão de produção e a criação de diferenciação.

Conforme Freeman apud Santos et al. (2011) define a inovação em quatro categorias: incremental, radical, mudanças do sistema tecnológico e mudança no paradigma. Inovações incrementais caracterizam-se pelo aperfeiçoamento ou melhorias no que já é realizado. Inovações radicais são de menor ocorrência, porem trazem maior novidade, normalmente é resultado dos esforços em P\&D (pesquisa e desenvolvimento). Mudanças do sistema tecnológico caracterizam-se por novos recursos tecnológicos que afetam todos os setores da empresa. Mudança no paradigma possui caráter revolucionário, tanto no tecnológico, social ou econômico e resulta em uma nova percepção paradigmática. No entanto, cabe ressaltar que inovação é um processo que é precedido por inúmeros fatores para atingir-se êxito na atividade inovadora. Desta forma autores como Bessant e Tidd (2009), Trias e Kotler (2012), e Govindarajan (2014) defendem que inovar não se limita apenas na criação de novas ideias, e sim em um processo estratégico e gerenciável, que possibilite a captação dessas ideias até sua aplicação, na qual requer que os objetivos e responsabilidades estejam implicitamente alinhados e definidos.

As percepções dos autores citados fundamentam o conceito de inovação para o estudo, sendo assim resume-se a inovação em buscar meios para explorar as oportunidades de mudanças, reinventando produtos ou processos para oferecer maior diferenciação para o mercado. A inovação pode incorrer em impactos internos como externos, promovendo pequenas mudanças, assim como revoluções em produtos (serviços) ou processos e, consequentemente reflete positivamente no desenvolvimento econômico local (SCHUMPTER 1985; OCDE, 2005).

\subsection{Inovação em serviços}

Cabe a inserção do tópico inovação em serviços devido às limitações e incoerências de algumas definições da inovação, pois a base fundamentadora do termo refere-se em análises, métodos e conceitos com ênfase na indústria manufatureira, (VARGAS et al., 2013).

O autor Gallouj (2010) identificou que as primeiras abordagens do tema inovação tinham como ênfase uma analise mecanicista de produção e não abrangiam a inovação tecnológica, pelo qual não se adequava a economia de serviços. O crescimento e a capacidade de movimentação econômica que o setor de serviços promoveu, possibilitou que a partir da década de noventa novas percepções pudessem abranger a inovação tanto aos bens tangíveis como em intangíveis.

A abordagem integradora é a que melhor se adéqua ao tema inovação em serviços, pois conforme Vargas et al. (2013) seu enfoque está na integração de bens tangíveis e intangíveis em uma mesma perspectiva analítica da inovação, onde mesmo com as especificidades, há características funcionais comum à produtos e serviços. Gallouj (2002) esclarece que a inovação não é um resultado e sim um processo, e aponta seis modelos de ocorrência de inovação: radical, de melhoria, incremental, ad hoc, por 
recombinação e por processo. Aborda-se a seguir uma visão sobre o tema inovação com ênfase nas tipologias que definem o processo de inovar e o tipificam.

\subsection{Tipologias de Inovação}

Compreender como as empresas inovam e qual o seu grau de inovação não é uma tarefa simples, requer uma analise detalhada e ampliada de sua atuação, seus processos e seu posicionamento no mercado. Se valendo disso a OCDE (2005) desenvolveu um manual denominado "O Manual de Oslo" que tornou-se uma das principais referencias mundiais para entendimento e mensuração da atividade inovadora de uma empresa. De acordo com o Manual de Oslo (OCDE, 2005) a inovação pode ser divida em quatro tipos: inovação de produto, inovação de processo, inovação de marketing e inovação organizacional.

Inovação de produto consiste em apresentar ao mercado um novo produto ou serviço com significativo grau de novidade, ou da mesma forma oferecer um produto já existente com melhorias significáveis e relevantes para seu usuário final. Isto implica em mudanças técnicas de componentes ou materiais, uso ou manuseio e características funcionais. Inovação em produto subdivide-se em: Novo produto ou serviço: caracteriza-se por oferecer ao cliente algo absolutamente diferente do que a empresa já oferece. Isto inclui também desenvolver um novo uso para determinado produto ou serviço; Melhoramentos significativos - consiste em utilizar-se de novos materiais, recursos tecnológicos ou inserção de novas funcionalidades a um produto ou serviço, de maneira que aprimore seu desempenho.

Inovações de processos representam mudanças nos métodos de produção ou distribuição do produto, com significativo grau de melhora. Sendo que se atribui a métodos de produção tudo que se relaciona com equipamentos, técnicas ou tecnologias que empresa se utiliza para produzir e, atribui-se método de distribuição à logística da empresa e seus recursos que envolvem a cadeia de suprimentos. Inovações de processo visam à redução de custo, aumento da qualidade, geração de novos produtos significativamente melhorados e a distribuição de maneira mais eficiente.

Inovações Organizacionais são "a implementação de um novo método organizacional nas práticas de negócios da empresa, na organização do seu local de trabalho ou em suas relações externas" (OCDE. p.34, 2005). Inovações organizacionais geralmente têm ênfase no ambiente interno e visam a melhora no desempenho da empresa, com reduções de custos e aumento da satisfação no local de trabalho. Esse tipo de inovação subdivide-se em inovações organizacionais práticas de negócio e inovações organizacionais no local de trabalho: As inovações em práticas de negócio abrange a implementação de novos métodos de rotinas e procedimentos para a execução do trabalho; As inovações no local de trabalho abrange a implementação de novos métodos de divisão e distribuição de responsabilidades, de maneira que possibilite aos empregados maior autonomia quanto a decisões em seus respectivos setores.

Inovação de Marketing consiste na implementação de um novo método de marketing estreitamente relacionado aos " 4 Ps" do Marketing (ponto, preço, produto e promoção) com significativa melhora em ambos. Inovações de Marketing visam atender necessidades do cliente, reposicionamento de produtos ou da marca e aumento de vendas. Embora o Manual de Oslo desenvolvido pela OCDE seja um dos modelos mais completos e utilizados em todo mundo devido a sua riqueza de informação e credibilidade. (SAWHNEY, WOLCOTT E ARRONIZ, 2006) Perceberam a necessidade de ampliar a perspectiva do termo inovação e, com base nos quatros tipos 
de inovação do manual, desenvolveram uma nova metodologia de avaliação, denominado de Radar da Inovação, que se utilizou no presente estudo.

\subsection{As dimensões da inovação - Radar da inovação}

O radar da inovação trata-se de um método que permite avaliar o grau de inovação de uma empresa através das dimensões inovadoras. Sawhney, Wolcott e Arroniz (2006) desenvolvedores do método, apontam quatro dimensões inovadoras principais e outras oito dimensões complementares pelo qual as empresas inovam. As quatro dimensões principais observadas pelo autor consistem em: ofertas, clientes, processos e presença. As oito dimensões complementares consistem em: plataforma, soluções, experiência dos clientes, captação de valor, organização, cadeia de suprimentos, redes e marca.

Ofertas - refere-se ao lançamento de novos produtos ou serviços da empresa para o mercado. Ainda para esta dimensão considera-se a entrada da empresa em novos mercados como uma inovação em oferta. Empresas inovadoras nesta dimensão detêm significativa parcela de sua receita através de novos produtos ou serviços.

Clientes - referem-se a indivíduos ou organizações que consomem ou se utilizam dos produtos ou serviços da empresa para atender as suas necessidades. Inovar nesta dimensão consiste em identificar demandas não atendidas de clientes ou segmentos de clientes sub-atendidos, ou mal atendidas.

Processos - refere-se às configurações que a empresa se utiliza para condução das operações internas. Inovar nesta dimensão consiste em redesenhar os processos visando melhorar eficiência, aumento na qualidade ou ciclos de tempo mais rápidos.

Presença - refere-se aos canais de distribuição que empresa utiliza para levar seus produtos ou serviços para o mercado. Inovar nesta dimensão representa a criação de novos canais de distribuição ou a utilização dos canais atuais de maneira mais criativa.

Plataforma - referem-se aos métodos, componentes tecnologias usadas como base no desenvolvimento de mais de um produto ou serviço. Inovar nesta dimensão pressupõe à modularização dos recursos utilizados na produção, visando oferecer maior numero de produtos distintos.

Soluções - consiste na personalização de produtos ou serviços, propondo opções complementares ou adicionais que atendam a necessidades especifica de seus consumidores. Inovar nesta dimensão consiste em criar soluções complementares aos produtos ou serviço, permitindo agregar maior valor ao cliente, assim como maior rentabilidade a empresa.

Experiência dos clientes - refere-se às percepções dos clientes quando relacionado com produtos ou serviços oferecidos pela empresa. Inovar nesta dimensão representa reavaliar ou redesenhar pontos de contato a fim de estreitar a interação com cliente, da mesma oferecer meios de manter o relacionamento com seus clientes.

Captação de valor - refere-se aos mecanismos criados pela empresa para recapturar o valor que criou. Inovar nesta dimensão representa explorar novas fontes de receitas, propor novas interações com cliente e parceiros.

Organização - refere-se ao modo de como está estruturada a empresa e como esta dividida as responsabilidades entre seus colaboradores. Para inovar nesta dimensão a empresa deve desenvolver meios de reorganizar funções e tarefas da para atender as demandas de mercado, bem como estabelecer parcerias visando agregar novos conhecimentos tecnológicos, compartilhamento de informações ou redução de custos. 
Cadeia de suprimentos - refere-se ao conjunto sequencial de atividades que movem o produto da origem a entrega, ou seja, ao cliente. Inovar nesta dimensão consiste em aperfeiçoar os processos da cadeia de suprimentos, promovendo medidas que melhorem o fluxo de informações, bem como o tempo de espera entre a entrega do produto ou conclusão do serviço para o cliente.

Rede - representa a conexão dos produtos ou serviços da empresa com seus clientes. Inovar nesta dimensão consiste em promover melhorias na rede que resultem em agregar maior valor aos produtos e serviços da empresa.

Marca - consistem nos símbolos, slogans pelo qual a empresa transmite sua imagem e seus clientes. Inovar nesta dimensão representa adotar novos meios criativos que alavanquem ou ampliem a marca da empresa no mercado. Neste estudo foi incluída uma décima terceira dimensão denominada ambiência inovadora, trata-se de uma percepção de Bachmann e Destefani (2008), o qual observou em seu estudo a inexistência da abordagem do ambiente como uma dimensão inovadora no método Radar da Inovação proposto por Sawhney, Wolcott e Arroniz (2006).

Ambiência inovadora Os autores, Bachmann e Destefani (2008) entendem que é fundamental dispor de um ambiente propicio a inovação, ressaltando esse fator como um pré-requisito para uma empresa inovadora. Para uma empresa inovar nesta dimensão é preciso promover uma cultura organizacional que aceite os erros e a ousadia em testar algo novo, permitir ao colaborador sugerir ideias que resultem em melhora nos processos da empresa, bem como nos seus produtos e serviços, procurar fontes externas de conhecimento, por meio de instituições de consultoria, representativas e centros técnicos ou universidades.

\section{Metodologia}

Para descobrir a problemática foi realizada uma pesquisa exploratória, que conforme Gil (2008) tem como objetivo a exploração do problema de pesquisa utilizando-se de fontes e meio de informações como entrevistas, pesquisa na internet, observações do pesquisador, possibilitando proporcionar maior familiaridade com o assunto. O método utilizado foi o estudo de caso que de acordo com YIN (2001, p.33) "um estudo de caso é uma investigação empírica que investiga um fenômeno contemporâneo dentro de seu contexto da vida real, especialmente quando os limites entre o fenômeno e o contexto não estão claramente definidos". A coleta de dados foi realizada por meio de uma entrevista presencial em quatro empresas do segmento de TICs da cidade de Pelotas escolhidas por aceitarem participar do estudo dentre as empresas conectadas, durante o período de 28 de abril de 2016 a 30 de maio do respectivo ano.

Estabeleceu-se como critério de seleção de empresas alvo do estudo, estas serem do segmento das TICs, estarem classificada como MPE e possuir mais de um ano de atuação no mercado. Foi incumbido ao gestor da empresa ou responsável designado à ocasião, responder aos questionários apresentados. A aplicação foi divida em dois questionários aplicados simultaneamente pelo pesquisador de forma presencial: Questionário de dados da empresa - pertinente a informações básicas da organização. $\mathrm{O}$ questionário do tipo misto, ou seja, composto por questões abertas e fechadas, totalizando dez questões; Questionário de avaliação do grau de inovação - abrangente as doze dimensões do radar da inovação de Sawhney, Wolcott e Arroniz (2006), bem como a inclusão da dimensão ambiência inovadora proposta por Bachmann (2008). O questionário do tipo fechado, ou seja, limitado às opções pré-dispostas no enunciado da questão, composto por vinte e oito questões. 
Quanto à abordagem dos dados foi utilizado o método qualitativo que de acordo com Minayo (2001) refere-se a analise do universo de aspectos, onde não é possível quantificar os significados, motivos, valores e crenças que estão estreitamente relacionados ao fenômeno a ser investigado. As questões referentes ao questionário avaliação do grau de inovação foram delimitadas por três opções de resposta, nesse caso, pouco ou nada inovadora, inovadora ocasional e inovadora sistêmica. Cada opção de resposta possui uma pontuação, que foi definida conforme a Figura 1:

\begin{tabular}{|c|c|}
\hline Pouco ou nada inovadora & 1 ponto \\
\hline Inovadora Ocasional & 3 pontos \\
\hline Inovadora Sistêmica & 5 pontos \\
\hline
\end{tabular}

Figura 1 Escala de inovação

Dessa forma para cada dimensão do radar da inovação foi atribuído no mínimo uma questão e no máximo três. Onde para descobrir o grau de inovação em cada dimensão foi utilizada uma simples equação: Grau de Inovação na dimensão $($ GId) $=$ Pontuação na dimensão / Número de Questões

A partir desta equação obtém se a pontuação do grau de inovação na respectiva dimensão. Após a aplicação da equação GId nas treze dimensões foi possível ter um panorama gráfico, por meio do radar da inovação. Para determinar o grau de inovação da empresa foi realizado um novo cálculo matemático, onde se somou cada dimensão da inovação resultando em uma pontuação total, que foi divido pelo numero de dimensões, como descrito a seguir: Grau de inovação na empresa (GIe) = Pontuação total $/ 13$

A partir da amostra coletada foram aplicadas as equações descritas anteriormente na qual os dados obtidos foram tabelados em planilha Excel e posteriormente gerados em gráfico radar. Resultando no grau de inovação das quatro empresas pesquisadas.

\section{Análise Dos Resultados}

Utilizando-se da metodologia radar da inovação coletaram-se as informações necessárias para avaliar o grau inovação em cada dimensão inovadora em cada uma das empresas pesquisadas, tanto como a grau de inovação da empresa. As doze dimensões propostas por Sawhney, Wolcott e Arroniz (2006) e a inclusão da dimensão ambiência inovadora proposta por Bachmann e Destefani (2008) possibilitaram a constituição do gráfico radar que avaliou as quatro empresas do ramo de TICs.

O Gráfico 1 apresenta as 13 dimensões da inovação em cada um de seus eixos, se valendo da escala pré-definida no método que vai de 0 a 5 , dessa forma para uma melhor visualização e interpretação entende-se que deve ser observado as linhas que indicam o desempenho da empresa, sendo que, quanto mais afastado do centro do gráfico radar, maior será seu grau de inovação da mesma forma que quanto mais próximo ao centro do gráfico será menor seu grau de inovação. 


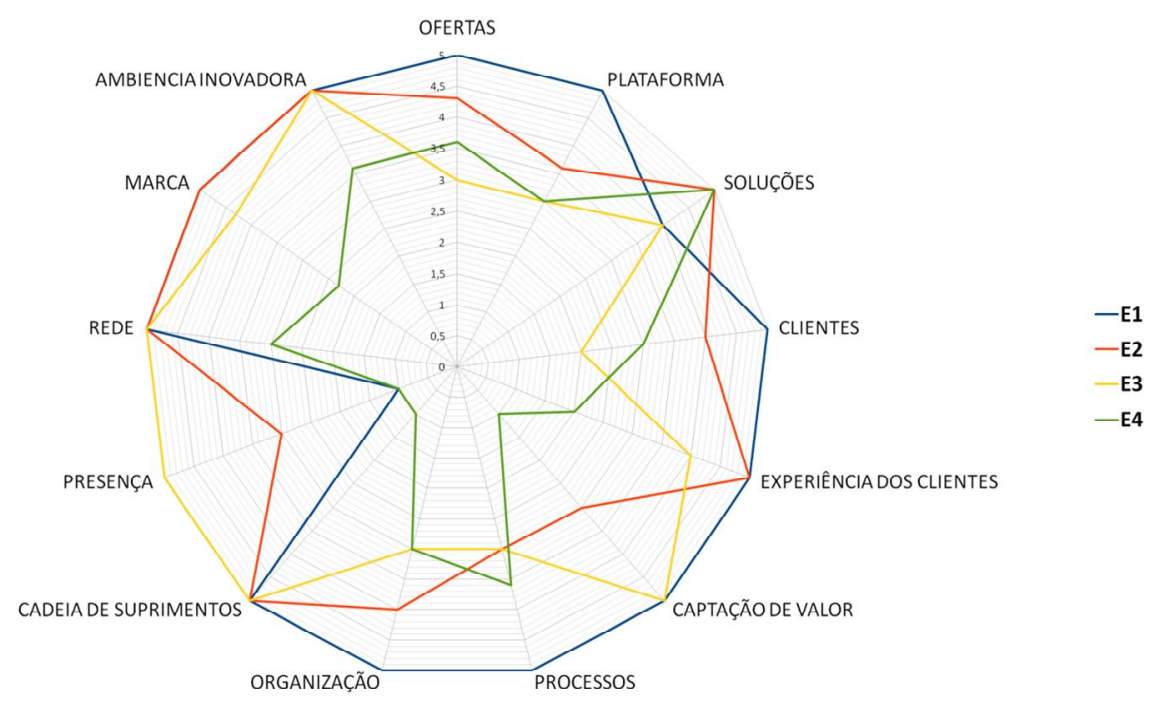

Gráfico 1 - Radar da Inovação

A dimensão oferta - a empresa 1 deteve escore máximo 5,0 atendendo a todos requisitos básicos para inovar nesta dimensão, que consistem na criação ou aperfeiçoamento de seus produtos ou serviços, vislumbrar uma fatia maior no mercado atual, tanto como oportunidade em novos e, utilização de novos recursos tecnológicos a fim de aumentar a diversidade de seu portfólio. A empresa 2 obteve para esta dimensão escore de 4,3, prezando pelo desenvolvimento e aperfeiçoamento de seus serviços concomitante a utilização de novos recursos com vistas a diversificação do portfólio. A empresa 3 nesta dimensão obteve escore 3,0 na qual sistematicamente busca a participação em novos mercados, e ocasionalmente inovam e seus serviços visando atingir um numero maior de clientes. A empresa 4 assim como as empresas 1 e 3 (E1, E3) preza pelo aperfeiçoamento de seus produtos e serviços e a oportunidade de atuar em novos mercados, seu grau de inovação nesta dimensão foi de 3,6.

Na dimensão plataforma - a empresa 1 novamente atingiu escore máximo de inovação 5,0, através do versionamento de seus produtos ou serviços visando atingir determinado grupo específico de clientes, modularização de seus serviços, assim como a multiutilização de recursos em novos produtos e serviços. A empresa 2 obteve escore 3,6 focando mais em identificar outros produtos ou serviços que possam ser oferecidos usando alguns dos componentes dos produtos ou serviços atuais. Já a empresa 3 tem em sua sistemática a modularização visando oferecer um maior número de soluções, seu escore na dimensão foi de 3,0. A empresa 4 obteve escore 3,0 e assim como as empresa 1 e 2 (E1, E2) preza pela multiutilização.

Para a dimensão soluções - as empresas 2 e 4 (E2, E4) apresentaram escore máximo no quesito de prover soluções complementares a seus principais serviços visando atender as necessidades dos clientes, da mesma forma o estabelecimento de parcerias com empresas que ofereçam produtos complementares para fornecer uma solução mais completa. As empresas 1 e 3 (E1, E3) obtiveram escore 4,0 na qual têm em sua sistemática prover soluções completares a seus clientes, e na ocasião promovem parcerias que possam complementar seus serviços.

Na dimensão clientes - a empresa 1 obteve escore máximo através da adoção de práticas de identificar demandas não atendidas de novos clientes ou segmentos de 
clientes sub atendidos ou mal atendidos, tanto como utilizar-se das sugestões de clientes ou usuários visando melhorar seus serviços. A empresa 2 obteve escore 4,0 onde ocasionalmente busca identificar demandas não atendidas, sub atendidas ou mal atendidas de clientes, da mesma forma sistematicamente utiliza-se das sugestões de seus clientes. A Empresa 3 atingiu escore 2,0 na qual conforme a ocasião utiliza-se de sugestões de clientes para melhorar seus serviços, porém não preza pela identificação de demandas de clientes não abrangidas pelo mercado. A empresa 4 preza pela identificação de demandas de clientes não atendidas e não promove melhorias em seus serviços a partir da sugestão de seus clientes, seu escore na dimensão foi de 3,0.

A dimensão experiência dos clientes - nas empresas 1 e 2 (E1, E2) apresentou escore 5,0 evidenciando inovação nas formas de interação com os clientes, seja na reavaliação ou no redesenho dos pontos de contato procurando estreitar o relacionamento e disponibilizar canais exclusivos para este tipo de interação. A empresa 3 obteve escore 4,0 e também disponibiliza um canal exclusivo de interação e ocasionalmente promove mudanças nas formas de estreitar a interação com seus clientes. A empresa 4 ocasionalmente reavalia seus pontos de interação com clientes, porém não disponibiliza meios exclusivos de interagir a não ser os por padrão telefone/celular e e-mail.

Na dimensão captação de valor - as empresa 1 e 3 (E1, E3) obtiveram escore 5,0 atingindo os requisitos básicos para inovar na dimensão, que refere-se em descobrir fluxos de receita não explorados e formas de captação de valor a partir de interações com clientes e parceiros. A empresa 2 ocasionalmente busca formas de obter receitas e obteve escore 3,0. A empresa 4 não possui nenhuma estratégia inovadora de captação de valor, desta forma não inova nesta dimensão.

Referente à dimensão processos - a empresa 1 atingiu escore máximo, evidenciando inovar em seus processos, através da reformulação com vistas a melhoria e eficiência, tanto como padronização e utilização de métodos para avaliar os processos a fim de propor melhorias. As empresas 2 e 3 (E2, E3) obtiveram escore 3,0 na dimensão, na qual tem em sua sistemática a padronização no desenvolvimento de seus serviços, e conforme a ocasião redesenham seus processos para resultarem em melhorias bem como a qualidade. A empresa 4 obteve escore 3,6 de acordo com as práticas adotadas pelo gestor, que sistematicamente preza pela redesenho de processos e a padronização do serviço. As empresas 2 e 34 (E2, E3, E4) não se utilizam de metodologias ou sistemas de avaliação de seus processos.

Dimensão organização - a empresa 5 obteve escore máximo atendendo a todos requisitos para inovar na dimensão, que refere-se a reorganização de funções e tarefas da empresa para atender as demandas de mercado, assim como estabelecer parcerias visando agregar novos conhecimentos tecnológicos, redução de custos e disseminação do conhecimento dentro da empresa. A empresa 2 obteve escore 4,0 onde possui em sua sistemática reorganizar-se para atender a demando e ocasionalmente propõe parcerias para contribuir com o desenvolvimento da empresa. As empresas 3 e 4 (E3 e E4) obtiveram escore 3,0 , na qual prezam pelo estabelecimento das parcerias como contribuição para o negócio, por outro lado não reorganizam funções e tarefas para atender as demandas do mercado.

Referente a cadeia de suprimentos - as empresas 1, 2 e 3 obtiveram escore máximo na dimensão 5,0, por meio da adoção de medidas que reduzam o tempo de entrega do produto ou serviço de maneira inovadora. A empresa 4 não adotou nenhuma medida quanto a sua cadeia de suprimentos, sendo considerado não inovadora nesta dimensão, seu escore foi 1,0 . 
A dimensão presença - trata de verificar se a empresa criou novas formas de distribuição de seus serviços ou aprimoramentos de seu ponto de distribuição de maneira inovadora, com objetivo de ocupar espaços no mercado. A empresa 3 atingiu escore máximo fazendo isso de forma inovadora. A empresa 2 faz de maneira ocasional obtendo escore 3. As empresas 1 e 5 (E1, E5) não inovam nesta dimensão, seus escores foi 1,0 .

Para a dimensão rede - as empresa 1, 2 e 3 (E1, E2 e E3) obtiveram escore 5,0. Adotando novas formas de ouvir ou falar com clientes através das mídias sociais, ferramentas de interação (web chats e acesso remoto) com objetivo de propor uma comunicação ágil e eficaz entre a empresa e seus clientes. A empresa 4 não inova nesta dimensão e seus escore é 1,0 .

A dimensão marca - as empresas 1 e 2 obtiveram escore 5,0 através da adoção de uma referencia visual associando ao serviço, lista de clientes de prestigio ou potenciais à marca da empresa, da mesma forma planejando meios de alavancar a marca de forma inovadora. A empresa 3 obteve escore 4,3 a partir das praticas de associação da marca ao serviço e seus clientes potenciais, e de forma ocasional planeja meios de alavancar a marca. A empresa 4 obteve escore 2,3 na dimensão, através da prática comumente adotada de associar a marca a lista de clientes potenciais.

Na dimensão ambiência inovadora - as empresas as empresas 1, 2 e 3 (E1, E2 e E3) obtiveram grau máximo de inovação, prezando pela busca de fontes externas de conhecimento através de instituições de consultoria, representativas e centros técnicos ou universidades, assim como suas culturas de valorização da ousadia em testar algo novo e aceitação dos erros em um ambiente informal que valorize os colaboradores que propõe sugestões para melhorias. A empresa 4 obteve escore de 3,6 atendendo aos principais requisitos para inovar na dimensão exceto o que refere-se a cultura de aceitação de erros e ousadia em testar algo novo no mercado.

\section{Considerações Finais}

O artigo teve o objetivo de avaliar o grau de inovação em quatro empresas que trabalham com a tecnologia da informação e comunicação da cidade de Pelotas-RS, através da metodologia do Radar da Inovação, o qual foi aplicado na íntegra o método e acrescentado a ambiência inovadora, pois na visão de Bachmann e Destefani (2008) para que se possa inovar é necessário um ambiente propício a inovação, e as doze dimensões proposta por Sawhney et al. (2006) não abrangerem esta avaliação do ambiente da empresa. Posteriormente, analisou-se os dados obtidos que possibilitaram ter um panorama de como as empresas abordadas tratam a inovação.

A partir disto, foi possível identificar o grau de inovação de cada empresa e especificamente suas treze dimensões, onde ressalta-se que o grau de inovação está estreitamente relacionado com a capacidade da empresa em inovar. Analisando do ponto de vista geral é possível afirmar que as empresas TICs abordadas são de fato inovadoras, embora algumas apresentaram menor grau de inovação que as demais, nesse caso as empresas 3 e 4 em relação as empresas 1 e 2 que obtiveram grau de inovação superior a 4,0 na escala que vai de 1 a 5 . É perceptível as ações de ambos os gestores em inovar, procurando sempre que possível e viável mudar algum aspecto seja, no serviço, no processo, no relacionamento com cliente ou no ambiente interno, visando agregar maior diferenciação e destacar-se no mercado. Sendo este um dos princípios defendidos por Schumpeter referente à empresa inovadora. Todavia, as empresas que apresentaram menor grau de inovação tendem a ter maior dificuldade para inovar. 
Complementando a análise geral, destaca-se que a inovação tem maior presença na dimensão ambiência inovadora, onde constatou-se que as empresas procuram promover um ambiente informal, pouco burocrático e que propicie a geração de novas ideias. Por outro lado, a dimensão presença é onde as empresas possuem menor grau de inovação, sendo ineficazes em propor novas formas de distribuição dos produtos/serviços, ou aprimorar os pontos já existentes de forma inovadora. Nestas empresas percebeu-se a utilização apenas do telefone e celular como uma forma de ponto de distribuição de seus serviços.

Em vista dos resultados identificados reafirma-se a importância da inovação para as empresas; assim como o planejamento para que as mudanças possam ocorrer de maneira continuada, da mesma forma evidencia-se a amplitude de formas para inovar em mais de um aspecto organizacional. Assim, o estudo verificou que as 12 dimensões proposta por Sawhney, Wolcott e Arroniz (2006) e a dimensão ambiência inovadora proposta por Bachmann e Destefani (2008) estão alinhadas para que as empresas possam, em primeiro momento, mensurar seu grau de inovação e, posteriormente propor ações visando aumentar o grau de inovação de uma ou mais dimensões, e consequentemente, aumentando a capacidade da empresa inovar sistematicamente, buscando a melhoria em seus processos e a inovação de todas as formas.

Como limitação ao estudo destaca-se a escolha das empresas abordadas deu-se de maneira aleatória e conforme a disponibilidade de cada gestor em participar do estudo, não havendo uma seleção por meio de um perfil com maiores características e detalhes, porém seguiu-se fielmente o perfil de empresa descrito na metodologia. Devido a este fato, a amostra não é significativa e por esse motivo não comporta generalizações, e sim apenas uma tendência do setor TICs.

Diante do objetivo e os resultados obtidos neste artigo, percebeu-se que esta discussão ainda pode comportar uma nova investigação, utilizando-se de uma ou mais dimensões inovadoras em vistas a identificar quais são os principais aspectos que contribuem ou dificultam, por exemplo, a inovação no ambiente organizacional, bem como qual a relação de um ou mais aspectos organizacionais com o grau de inovação em uma dimensão. Assim, sugere-se que outros estudos sobre inovação, fatores motivadores e quais mudanças proporcionam um maior impacto no negócio, são importantes e salutares, como forma de aprofundar o assunto e trazer informações mais precisas para os empresários e para o setor.

\section{Referências}

BACHMANN, D. L.; DESTEFANI, J. H. Metodologia para estimar o grau das inovações nas MPE. 2016.

BESSANT, J.; TIDD, J. Inovação e empreendedorismo. S/L: Bookman. 2009.

GALLOUJ, F.; DJELLAL, F. Introduction: filling the innovation gap in the service economy - a multidisciplinary perspective. In: Gallouj, F; Djellal, F. The Handbook of Innovation in Services: a Multi-disciplinary Perspective. Edward Elgar, UK / USA. 2010.

GONVIDARAJAN, V. O Desafio da Inovação: Fundamentos Para Construir Empresas Inovadoras Em meio a incertezas e complexidades. Rio de Janeiro: Elsevier. 2014. 
GRANO, N. Empreendedorismo inovador: como criar Startups de Tecnologia no Brasil. São Paulo: Évora. 2012.

MINAYO, M. C. S. Pesquisa social: teoria, método e criatividade. Petrópolis: Vozes. 2001.

SANTOS, A. B. A.; FAZION, C. B.; MEROE, G. P. S. Inovação: um estudo sobre a evolução do conceito de Schumpeter. 2016.

SCHUMPETER, J. A. Teoria do Desenvolvimento Econômico. São Paulo: Nova Cultural. 1985.

TRIAS, F. B.; KOTLER, P. A Bíblia da Inovação. São Paulo: Leya. 2012.

VARGAS, E. R.; BOHRER, C. T.; FERREIRA, L. B.; MOREIRA, M. F. A pesquisa sobre inovação em serviços no Brasil: estágio atual, desafios e perspectivas. 2010.

YIN, R. K. Estudo de caso: planejamento e métodos. 2 a edição. Porto Alegre: Bookman. 2001. 